\title{
Intracellular Recordings Reveal Novel Features of Neurons That Code Interaural Intensity Disparities in the Inferior Colliculus
}

\author{
Na Li, ${ }^{1,2,3}$ Joshua X. Gittelman, ${ }^{1,2,3}$ and George D. Pollak ${ }^{1,2,3}$ \\ ${ }^{1}$ Section of Neurobiology, ${ }^{2}$ Institute for Neuroscience, and ${ }^{3}$ Center for Perceptual Systems, The University of Texas at Austin, Austin, Texas 78712
}

\begin{abstract}
Many cells in the inferior colliculus (IC) are excited by contralateral and inhibited by ipsilateral stimulation and are thought to be important for sound localization. These excitatory-inhibitory (EI) cells comprise a diverse group, even though they exhibit a common binaural response property. Previous extracellular studies showed the diversity results from different circuits that generate the same EI property among the IC population, where some inherit the property from a lower nucleus, some are formed de novo in the IC, and others inherit EI features that are modified by inhibitory circuits. Here we evaluated the differential circuitry by recording inputs (postsynaptic potentials) and outputs (spikes) with in vivo whole-cell recordings from the IC of awake Mexican free-tailed bats. We show that in a minority of EI cells, either they inherited their binaural property from a lower binaural nucleus or the EI property was created in the IC via inhibitory projections from the ipsilateral ear, features consistent with those observed in extracellular studies. However, in a majority of EI cells, ipsilateral signals evoked subthreshold EPSPs that behaved paradoxically in that EPSP amplitudes increased with intensity, even though binaural signals with the same ipsilateral intensities generated progressively greater spike suppressions. We propose circuitry that can account for the responses we observed and suggest that the ipsilaterally evoked EPSPs could influence the responsiveness of IC cells to dynamic signals with interaural intensity disparities that change over time, such as moving sound sources or multiple sounds that occur in complex acoustic environments.
\end{abstract}

\section{Introduction}

Interaural intensity differences (IIDs) are the cues that animals use to localize high-frequency sounds (Erulkar, 1972; Mills, 1972). The intensities received at the two ears are coded in the auditory nerve and are first "compared" by binaural neurons in the lateral superior olive (LSO). The comparison is subtractive, whereby signals from one ear excite and signals from the other ear inhibit the binaural cells, and thus these excitatory/inhibitory (EI) neurons are sensitive to intensity disparities (Caird and Klinke, 1983; Moore and Caspary, 1983; Joris and Yin, 1995; Park et al., 1996, 1997; Casseday et al., 2002).

The LSO sends its axonal projections bilaterally to both the inferior colliculus (IC) and the dorsal nucleus of the lateral lemniscus (DNLL). The DNLL is located just below the IC and sends strong GABAergic projections to the IC just above it and to the opposite IC. The IC is of particular interest because it receives the projections not only from the two LSOs and DNLLs, but also from most other lower auditory nuclei, and thus is the nexus of the auditory system (Oliver and Huerta, 1992; Casseday et al., 2002). Consistent with its innervation from the LSO, many IC cells express EI properties similar to those in the LSO (Roth et al.,

\footnotetext{
Received April 30, 2010; revised June 11, 2010; accepted Sept. 6, 2010.

This work was supported by National Institutes of Health Grant DC007856. We thank Sari Andoni, Nace Golding, Andrew Tan, and Michael Burger for helpful comments and discussions. We also thank Carl Resler for technical support.

Correspondence should be addressed to $\mathrm{Na}$ Li at the above address. E-mail: nalibat@mail.utexas.edu. DOI:10.1523/JNEUROSCI.2228-10.2010

Copyright $\odot 2010$ the authors $\quad 0270-6474 / 10 / 3014573-12 \$ 15.00 / 0$
}

1978; Wenstrup et al., 1986; Irvine and Gago, 1990; Kelly et al., 1991).

The EI cells in the IC, however, comprise a diverse group, even though they exhibit binaural response properties similar to LSO cells. The diversity is apparent from the changes in EI properties when inhibition at the IC is blocked or the DNLL is reversibly inactivated (Li and Kelly, 1992; Faingold et al., 1993; Park and Pollak, 1994; Burger and Pollak, 2001). Previous studies proposed specific excitatory and/or inhibitory events that should be evoked by each ear and thereby generate each of the various types of EI cells in the IC via the projections shown in Figure 1. The synaptic events proposed for each of the circuits, however, could not be directly observed with extracellular recordings but rather were inferred from the changes in discharge properties due to blocking inhibition. To evaluate the degree to which the proposed synaptic events actually occur, we used in vivo whole-cell recordings from the IC in awake bats to directly visualize both the inputs to EI cells, as revealed by sound-evoked EPSPs and IPSPs, and the outputs, the discharges evoked by both monaural and binaural signals. We show that in a minority of cells the postsynaptic potentials (PSPs) evoked by monaural and binaural signals are consistent with the synaptic events proposed in previous extracellular studies to account for the various formations of EI properties. In the majority of EI cells, however, ipsilateral signals evoked subthreshold EPSPs. The EPSPs behaved paradoxically in that the EPSP amplitudes increased with intensity, even though binaural signals with the same ipsilateral intensities generated progressively greater spike suppressions. These additional sub- 
A

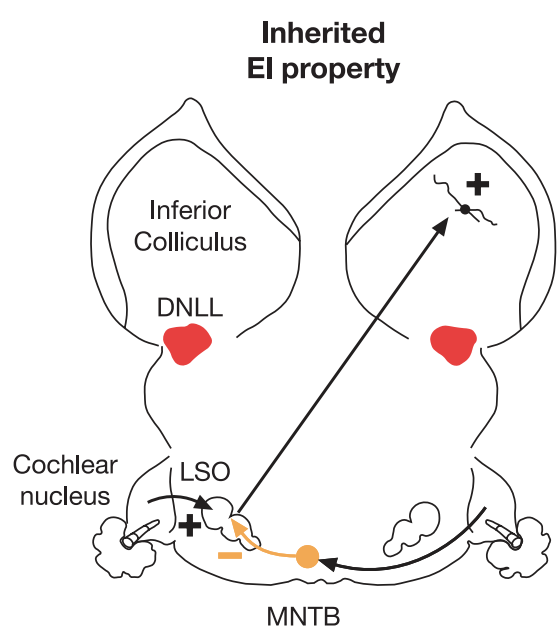

Control

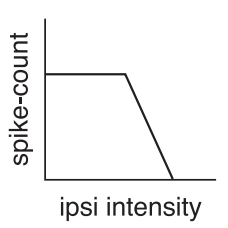

Inhibition

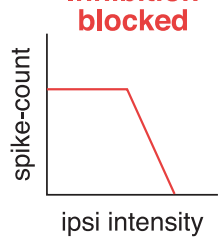

B

de novo

El property

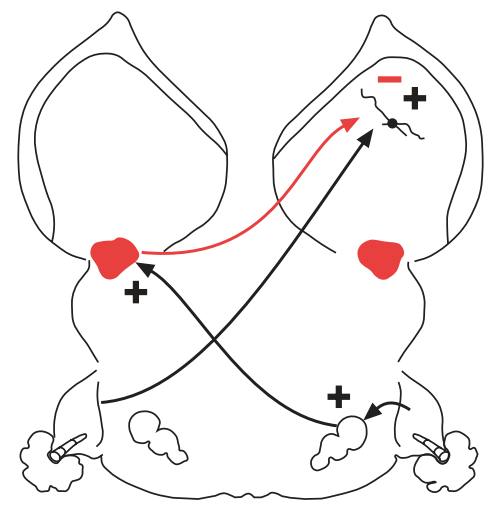

Control

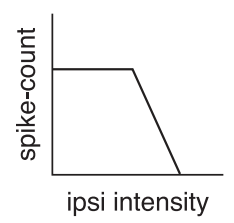

Inhibition

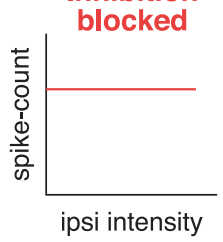

C

Hybrid El property

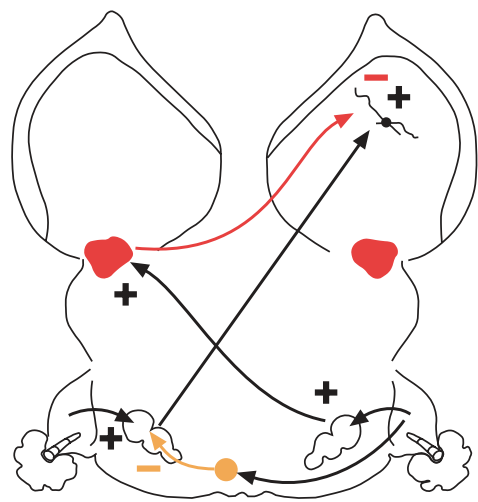

Control

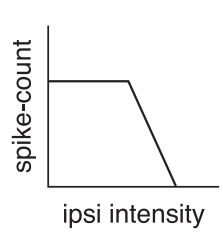

Inhibition

blocked

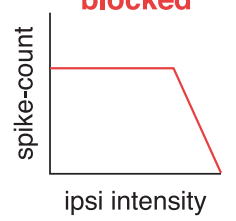

Figure 1. Circuitry proposed in previous reports to account for the changes in binaural properties of El cells when inhibition was blocked or the DNLL contralateral to the IC was inactivated. Black lines show excitatory and red lines show inhibitory projections. Lower graphs show changes in IID functions obtained before and while inhibition was blocked. $\boldsymbol{A}$, El property is assumed to be inherited from the LSO when there is no change in the IID function while inhibition is blocked at the IC. $\boldsymbol{B}$, El property is created in IC from excitatory projections evoked by contralateral stimulation and inhibitory projections from the opposite DNLL that are activated by ipsilateral stimulation. In these cells, blocking GABAergic inhibition at the IC or inactivating the opposite DNLL greatly reduces or completely abolishes the ipsilateral evoked spike suppression and transforms an El into a monaural cell. C, Hybrid formation of El properties. In these cells, the El property is inherited from the LSO, but the inhibitory projections from the DNLL cause spike suppression at lower ipsilateral intensities than those generated by the LSO. Hence, blocking inhibition or reversibly inactivating the DNLL does not abolish the El property but causes a shift in the IIDs that generate the spike suppression.

threshold responses not only show that the circuitry underlying EI cells is more complex than previously suspected but also suggest that the additional EPSPs could influence the responsiveness of EI cells to signals that generate IIDs that change over time, such as moving sound sources or multiple sounds that occur in complex acoustic environments.

\section{Materials and Methods}

Surgical procedures. Experiments were conducted on male Mexican freetailed bats, Tadarida brasiliensis mexicana, captured from local sources in Austin, TX. Surgical procedures were as described in previous reports (Xie et al., 2008; Gittelman et al., 2009). In brief, bats were sedated with isoflurane (inhalation) and then anesthetized with an intraperitoneal injection of ketamine/xylazine (75-100 mg/kg ketamine, $11-15 \mathrm{mg} / \mathrm{kg}$ xylazine, Henry Schein). The muscles and skin overlying the skull were reflected, a foundation layer of cyanoacrylate was placed on the surface of the skull, and a small metal rod was cemented to the foundation layer on the skull and then attached to a bar. The IC in bats is hypertrophied and can be seen through the thin brain case protruding between the cortex and cerebellum. An opening was made in the skull over the IC and the brain was kept clean and moist with Ringer solution. The bat was placed in a restraining cushion and in the stereotaxic device, and the bar on its head was secured to the stereotaxic device. Recordings were begun after the bats recovered from the anesthetic, and thus all data were obtained from awake animals. The bats typically lay quietly during the remainder of the experiments. If they showed signs of discomfort, data collection was stopped and doses of the neuroleptic, ketamine hydrochloride (1/40 dilution, $0.01 \mathrm{cc}$ injection, Henry Schien), were administered. If they continued to show signs of discomfort, the experiments were terminated. All experimental procedures were in accordance with a protocol approved by the University of Texas Institutional Animal Care Committee.
Acoustic stimuli. Auditory stimuli were tone bursts generated digitally in IGOR-PRO. Tone bursts had durations of 5-20 ms and rise-fall times of $0.2 \mathrm{~ms}$. The acoustic signals were sent to an Instrutech 16-bit D/A converter and were fed to custom-made electronic attenuators and then to custom-designed earphones. The frequency characteristics of each earphone was determined with a $1 / 4$ inch Bruel and Kajer microphone, and the computer compensated for output fluctuations across frequency so that each earphone was flat $\pm 2 \mathrm{~dB}$ from $\sim 10-50 \mathrm{kHz}$. At the start of each experiment, the earphone was inserted into the funnel formed by the bat's pinnae and positioned adjacent to the external auditory meatus. The acoustic crosstalk with this arrangement is $\sim 40 \mathrm{~dB}$.

Recording procedures and data acquisition. Responses were recorded with patch electrodes $(5-10 \mathrm{M} \Omega)$ pulled from thick-walled $(1.65 \mathrm{~mm}$ OD, $1.1 \mathrm{~mm}$ ID) capillary glass (WPI, \#PG52165-4). The standard internal solution was as follows (in mM): K-gluconate (115), HEPES (10), $\mathrm{KCl}$ (7), MgATP (4), $\mathrm{Na}_{2} \mathrm{GTP}$ (0.3), EGTA (0.5), and $\mathrm{Na}_{2}$-phosphocreatine (10). Membrane potentials were not corrected for liquid junction potentials.

During experiments, the electrodes were positioned over the IC and lowered into the IC with a piezoelectric microdrive (Burleigh Inchworm; EXFO Burleigh) while under positive pressure of 2-3 psi. Electrodes were lowered to a depth of $\sim 300 \mu \mathrm{m}$ to bypass the external nucleus of the IC and ensure that recordings were made from cells in the central nucleus of the IC. All cells were recorded at depths of $300-1000 \mu \mathrm{m}$ from the surface of the IC. Upon entering the central nucleus, the pressure was reduced to $0.3-0.7 \mathrm{psi}$ and the electrodes were advanced in steps of $1-2 \mu \mathrm{m}$. Cell search was conducted in voltage-clamp mode using a $-5 \mathrm{mV}$ step to monitor electrode resistance. When contact with a cell was made, pressure was released and a small amount of negative pressure $(<0.5 \mathrm{psi})$ was applied to obtain a gigaohm seal. After a seal was obtained, additional negative pressure was applied to break-in, the amplifier was switched to 
A

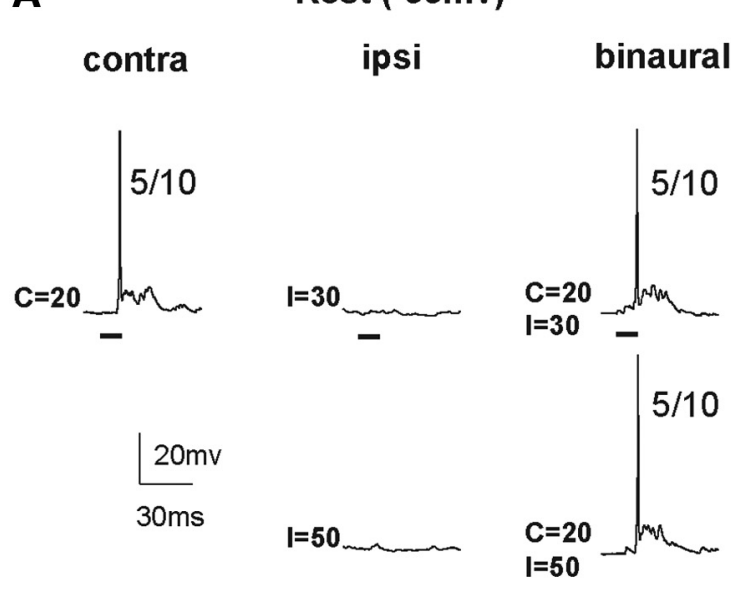

\section{B Hyperpolarized $(-73 \mathrm{mv})$

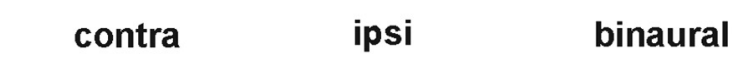

A contra Rest (-57mv) ipsi

\section{binaural}

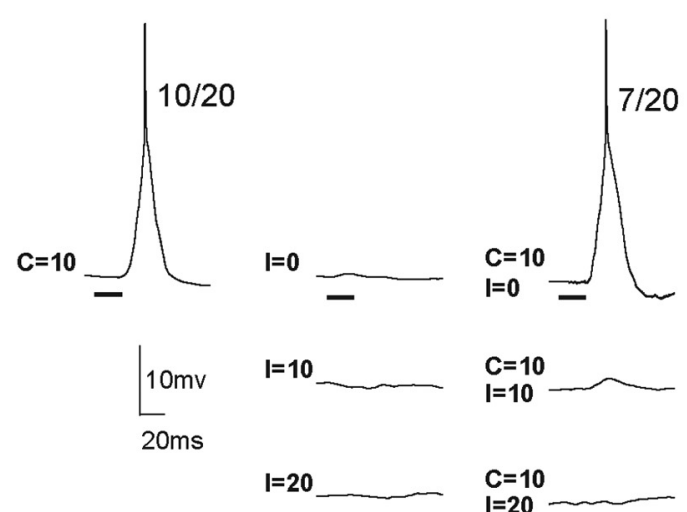

B

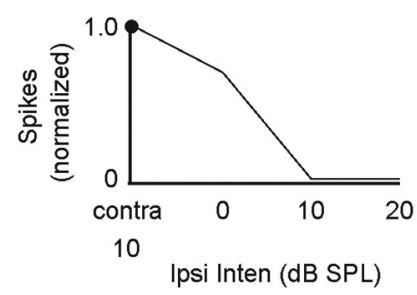

C $\begin{gathered}\text { Hyperpolarized }(-82 \mathrm{mv}) \\ \text { contra ipsi binaural }\end{gathered}$
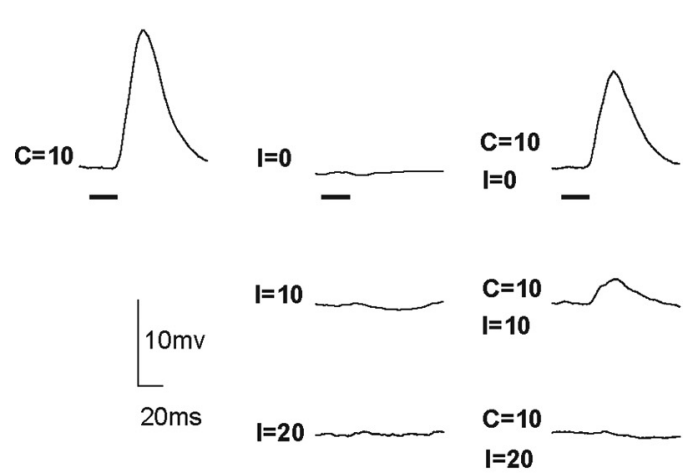

D

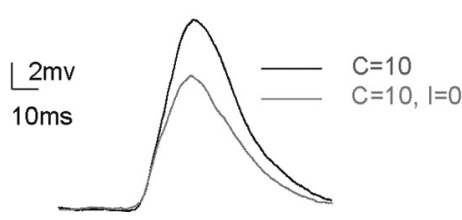

Figure 3. An El cell in which the contralaterally evoked spikes were completely suppressed by ipsilateral tones, but ipsilateral tones presented alone evoked no responses. The El property was inherited from a lower binaural nucleus, and the circuit that most likely generated the responses is shown in Figure $1 A . A$, Responses evoked by contralateral, ipsilateral, and binaural tones at the resting membrane potential. Ipsilateral tones presented monaurally evoked no responses at 0,10 , or $20 \mathrm{~dB}$ SPL, even though binaural tones with ipsilateral intensities of $10-20 \mathrm{~dB}$ completely suppressed spikes. $\boldsymbol{B}$, IID function showing the binaural spike counts normalized to the count evoked by the contralateral tone alone as a function of ipsilateral intensity. $C$, Responses to the same stimuli while the cell was hyperpolarized from $-57 \mathrm{mV}$ to $-82 \mathrm{mV}$. The hyperpolarization prevented spiking, and a large EPSP was evoked by the contralateral tone at $10 \mathrm{~dB}$ SPL. Ipsilateral signals presented monaurally did not evoke any discernible response, showing that the cell did not receive ipsilateral innervation. With binaural signals, however, the EPSPs evoked by the contralateral tones were progressively suppressed by ipsilateral tones until the EPSP was abolished when the ipsilateral intensity was $20 \mathrm{~dB}$ SPL. D, EPSPs evoked by contralateral tone alone are overlaid with those evoked by binaural tone, showing that an ipsilateral tone of $0 \mathrm{~dB}$ SPL reduced the amplitude of the EPSP evoked by the contralateral tone. Tone duration, $20 \mathrm{~ms}$. 
was manually scanned to determine the cell's best frequency $(\mathrm{BF})$, the frequency at which the lowest intensity evoked discharges. BF tones were then presented to evaluate responses evoked by contralateral, ipsilateral, and binaural stimulation. Each tone was presented $8-20$ times. In each of the figures below, the recordings that show EPSPs with spikes are from a single tone presentation, while each subthreshold PSP shown is the average of the 8-20 tone presentations. The spike counts evoked by the particular number of tone presentations are shown on the right of each suprathreshold record.

\section{Results}

We recorded spikes and PSPs intracellularly with patch electrodes from 42 cells in the central nucleus of the IC of awake bats. Resting membrane potentials were not corrected for liquid junction potentials and ranged from -45 to $-57 \mathrm{mV}$ and were more or less evenly distributed among the various types of EI cells described below. All responses were evoked by tone bursts having durations of 5-20 ms presented at the neuron's BF. Tones were presented monaurally over a range of intensities to either the contralateral or ipsilateral ear alone. Binaural signals were presented with the tone at the contralateral ear fixed at one intensity, usually $\sim 10$ $\mathrm{dB}$ above spike threshold, while tones were presented simultaneously to the ipsilateral ear over a $20-40 \mathrm{~dB}$ intensity range, from $\sim 10 \mathrm{~dB}$ below to $30 \mathrm{~dB}$ above the intensity at the contralateral ear.

We recorded three major aural types of IC cells based on their responses to monaural and binaural stimulation. The three types were described in previous extracellular studies of the IC in bats and other mammals (Roth et al., 1978; Fuzessery et al., 1985; Semple and Kitzes, 1987; Li and Kelly, 1992; Park and Pollak, 1993). The first type is monaural. These cells, which comprised $\sim 7 \%$ of our sample ( $3 / 42$ cells), were driven by contralateral stimulation, but no discharges were evoked by ipsilateral stimulation (Fig. 2). Most importantly, the spike counts evoked by contralateral tones were not affected by tones presented simultaneously to the ipsilateral ear, even when the ipsilateral tones were $10-30 \mathrm{~dB}$ more intense than the contralateral tones. The second type is EI and was the most common type we recorded (67\%, 28/42 cells) (Fig. 3). Similar to the monaural cells described above, these cells were driven only by contralateral stimulation, and ipsilateral tones never evoked discharges. Unlike monaural cells, contralaterally evoked spike counts were inhibited when ipsilateral tones were presented simultaneously, hence the term excitatory-inhibitory. The third type is the facilitated EI (EI/f) cell, which comprised 26\% (11/42) of our sample (see Fig. 9). These cells differed from conventional EI cells in that binaural signals with low ipsilateral intensities evoked spike counts at least $20 \%$ higher than the counts evoked by the contralateral signals alone. As ipsilateral intensity increased, however, spikes were progressively suppressed and were
A contra
ipsi
binaural
B
contra
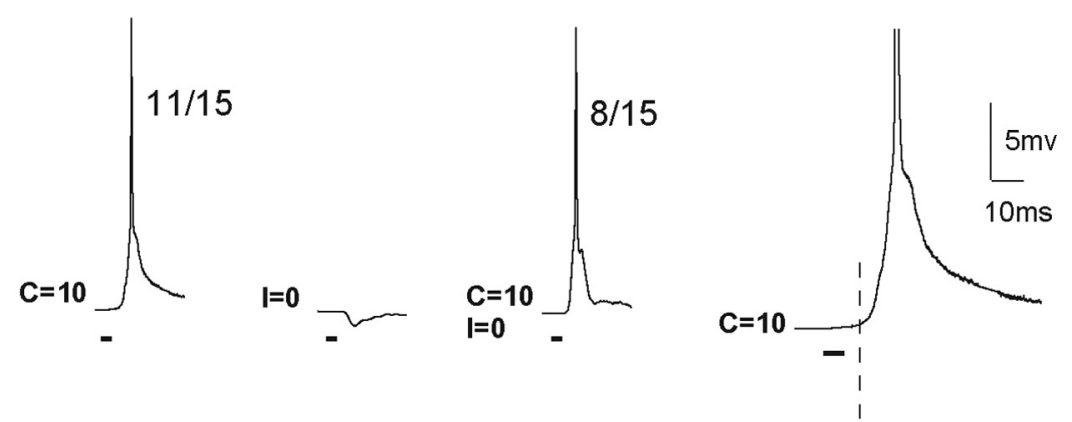

ipsi
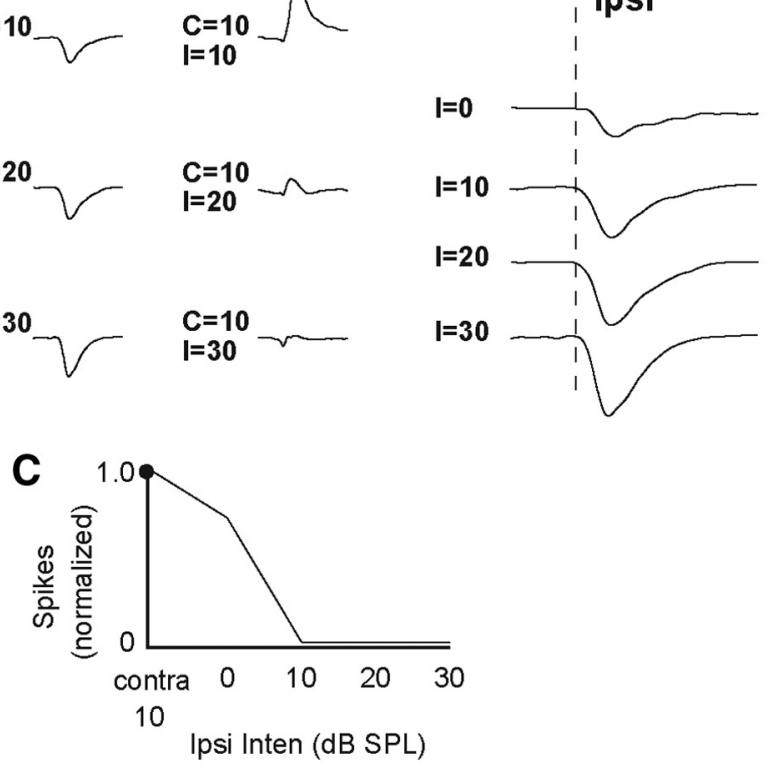

Figure 4. $\quad \boldsymbol{A}$, An El cell in which a contralateral tone evoked a suprathreshold EPSP and ipsilateral signals only evoked IPSPs that ing that the El property was created de novo in the IC with the circuitry shown in Figure $1 B$. B, Excitatory response to a $10 \mathrm{~dB}$ SPL contralateral tone aligned with IPSPs evoked by ipsilateral tones at different intensities, showing that the latencies of the IPSPS were coincident with the EPSP evoked by a contralateral tone. C, III function of spike counts. Tone duration, $5.0 \mathrm{~ms}$.

completely suppressed with ipsilateral signals $10-30 \mathrm{~dB}$ more intense than the contralateral signals.

In the sections below, we first describe the various projection patterns that were proposed in previous studies to account for the different formations of EI cells in the IC. The projections are shown in Figure 1. In the subsequent sections, we focus on PSPs, both EPSPs and IPSPs. Particular attention is directed at the PSPs evoked by monaural stimulation of the ipsilateral ear. In each case, we suggest how the interactions of the synaptic events evoked by each ear influenced the discharges evoked with binaural stimulation, and how those features relate to the projection patterns in Figure 1.

\section{Circuits proposed in previous studies that account for the} spike suppression by ipsilateral tones

All cells whose contralaterally evoked discharges were suppressed with binaural stimulation were categorized as EI or EI/f. There are, however, three explanations that can account for the suppression of contralaterally evoked discharges with binaural stimulation, the EI property, based on the excitatory and inhibitory 


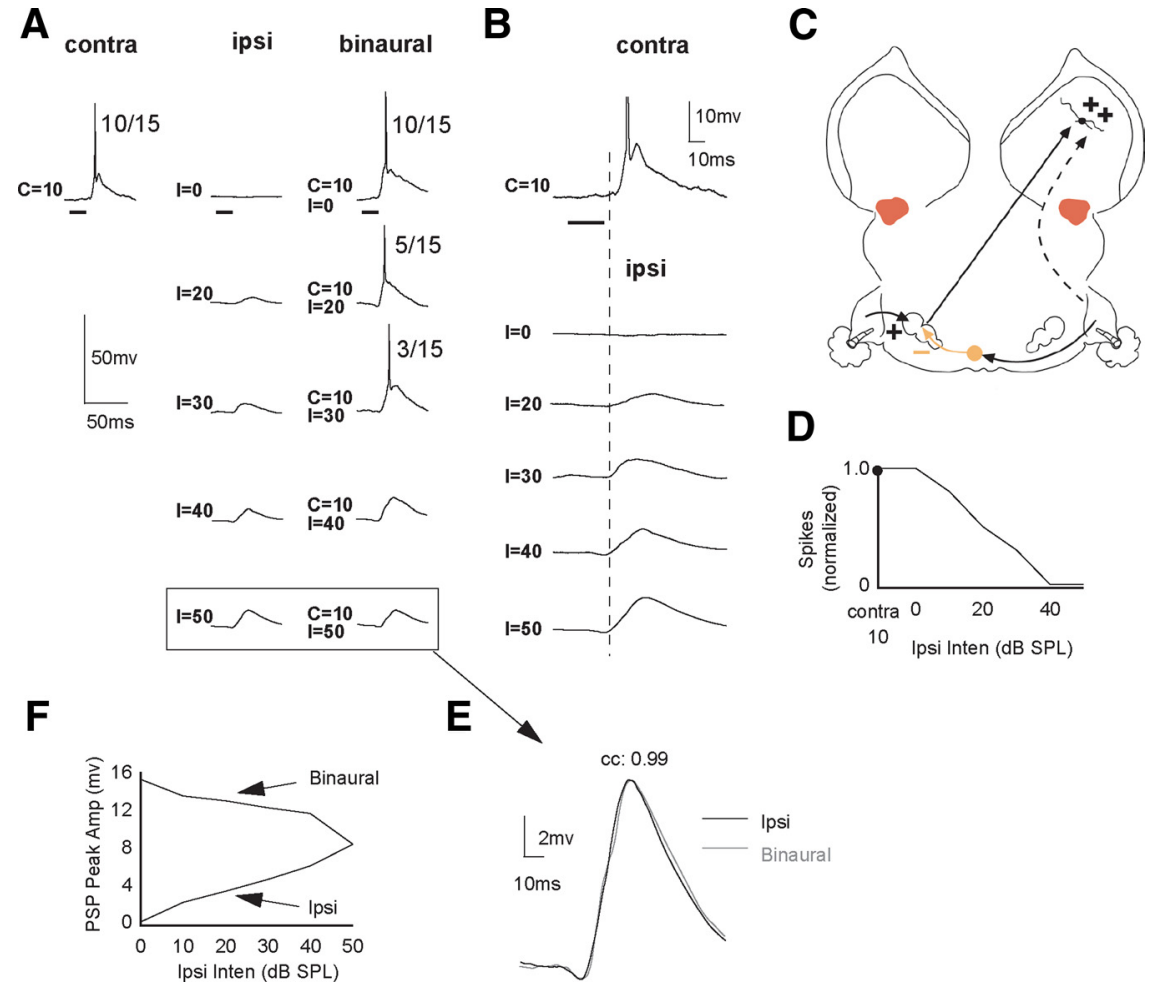

Figure 5. An El cell in which ipsilateral tones evoked only EPSPs with amplitudes that increased with intensity. When the same ipsilateral signals were presented binaurally, they strongly suppressed contralaterally evoked spikes. $\boldsymbol{A}$, Responses evoked by contralateral, ipsilateral, and binaural signals. Bracketed responses show the response to the ipsilateral tone at $50 \mathrm{~dB}$ SPL and the response to a binaural tone with the same, $50 \mathrm{dBSPL}$ ipsilateral intensity. $\boldsymbol{B}$, Same response to contralateral and ipsilateral tones as in $A$, but contralateral and ipsilateral tones are aligned in time and shown at higher magnification. $C$, Circuit that could generate the responses. $\boldsymbol{D}$, IID function in which normalized spike counts are plotted as a function of ipsilateral intensity. Contralateral intensity was $10 \mathrm{~dB}$ SPL. $\boldsymbol{E}$, The responses below the arrow are the two responses in brackets but are superimposed at a higher magnification. Amplitude of EPSPs are $\sim 8.0 \mathrm{mV}$. F, Amplitudes of ipsilaterally evoked EPSPs plotted together with the amplitudes of the EPSPs evoked by binaural signals that had the same ipsilateral intensities. Note that ipsilateral EPSP amplitudes increased with sound intensity, whereas the binaurally evoked EPSPs decreased with the same ipsilateral intensities. EPSP amplitudes of binaural signals were measured after spikes were eliminated. Tone duration, $20 \mathrm{~ms}$.

projections that innervate the IC (Fig. 1) (Li and Kelly, 1992; Faingold et al., 1993; Burger and Pollak, 2001; Pollak et al., 2003). The facilitation evoked by binaural signals in EI/f cells and the projection that could explain just the facilitation are considered in the following sections. One explanation is that the EI property was formed in a lower nucleus, presumably the LSO, and that property was then imposed on the IC cell via an excitatory projection (Fig. 1A). The EI property would, in that case, be inherited. Alternatively, the EI property may have been formed in the IC through a monaural excitatory projection evoked by sound at the contralateral ear that was then shaped by inhibitory inputs to the IC cell evoked by the ipsilateral ear, e.g., from the DNLL on the opposite side. The binaural property in this case would be created de novo in the IC by the interactions of the synaptic events at the IC that were evoked by stimulating each ear (Fig. $1 B$ ). A third explanation is that yet other EI cells were hybrids, in that they had features of both types described above. In these cells the EI property is first formed in the LSO. The EI property, however, is modified in the IC through the convergence of LSO and inhibitory projections that presumably come from the DNLL. The net effect of this convergence is to create EI cells in the IC that are suppressed by lower intensities at the ipsilateral ear than they would be if they received only the LSO projection (Fig. 1C). Below we show the PSPs that were evoked by stimulation of each ear and how their interactions could account for the binaural dis- charge properties observed in each cell. We also point out the degree to which the circuits in Figure 1 can account for the results we observed in the various types of EI cells with patch electrodes.

\section{Postsynaptic potentials evoked by monaural and binaural stimulation in monaural cells}

In Figure 2, we first show the responses, PSPs and spikes, evoked in a monaural cell to provide a baseline for comparison with the EI and EI/f cells considered below. Consistent with the criteria given above for monaural cells, the spike counts evoked by contralateral tones were not affected by tones presented simultaneously to the ipsilateral ear, and ipsilateral stimuli presented alone evoked no detectable IPSP or EPSP at any intensity. As a further check to ensure that ipsilateral stimulation did not evoke either a shunting inhibition, where the resting potential was at or near the chloride equilibrium potential, or an inhibition that canceled an excitation, we hyperpolarized the membrane potential from its normal resting potential of -55 to $-73 \mathrm{mV}$ (Fig. $2 \mathrm{~B}$ ). Ipsilateral signals did not evoke a PSP during hyperpolarization at any intensity, thereby confirming that no subthreshold response was evoked by ipsilateral stimulation. Although the hyperpolarization prevented spiking, contralateral stimulation alone evoked a large EPSP due to the increase in the excitatory driving force. With binaural signals, increasing the ipsilateral intensity did not reduce the amplitudes of the EPSPs, which were equal to the amplitudes evoked by the contralateral signal presented alone (Fig. 2C). All of these features show that ipsilateral stimulation had no effect on the synaptic events evoked by contralateral stimulation. The finding that ipsilateral signals evoked no response, even when the ipsilateral signals were $30 \mathrm{~dB}$ louder than the contralateral signals, also showed that there was no speaker crosstalk at those intensities, i.e., that sound presented to one ear did not leak over to stimulate the other ear.

\section{Postsynaptic potentials evoked in EI cells}

Although all EI cells were homogenous in terms of their spike suppression with binaural stimulation, three different types of EI cells were observed based on the PSPs, or absence of PSPs, evoked by ipsilateral stimulation. The first type of EI cell (5/28) was similar to monaural cells, in that no PSP was evoked by ipsilateral stimuli, although the same ipsilateral signals, when presented binaurally, suppressed the discharges evoked by contralateral signals. These features are consistent with the circuit in Figure $1 \mathrm{~A}$ and are illustrated by the cell in Figure $3 A$. To ensure that the ipsilateral signals did not evoke a shunting inhibition, the cell was hyperpolarized from rest $(-57 \mathrm{mV})$ to $-82 \mathrm{mV}$ (Fig. 3C). Like the monaural cell described above, there were no PSPs evoked by ipsilateral stimulation while the cell was hyperpolarized. However, as the ipsilateral intensity increased during hyperpolarization, the PSPs evoked by binaural tones were progressively 
reduced in amplitude, and there was no discernible PSP at the highest ipsilateral intensity, i.e., when the ipsilateral tone was 20 $\mathrm{dB}$ sound pressure level (SPL). Our explanation for these results is that IC cell only received excitatory inputs from a lower nucleus that was driven by stimulation of the contralateral ear. The lower nucleus, however, was binaural and had EI properties, e.g., LSO, and those properties were then imposed on the IC cell through an excitatory projection, as shown in Figure $1 A$. Thus, the ipsilateral inhibition of contralaterally evoked discharges occurred in the lower nucleus, and the EI properties of these IC cells were inherited.

The second type (3/28 EI cells) had ipsilaterally evoked IPSPs that most likely inhibited the contralaterally evoked excitation, and thereby formed the EI property in the IC, features consistent with the circuit in Figure $1 B$. Three features of the IPSPs are noteworthy and are illustrated by the EI cell in Figure 4 . The first feature is that the ipsilateral inhibition was intensity dependent, where the IPSP magnitudes progressively increased with ipsilateral intensity in a manner that mirrored the intensity-dependent spike suppression. The second is that the latencies of the IPSPs were similar to the latencies of the contralaterally evoked excitation, where the inhibition and excitation overlapped extensively and were coincident at ipsilateral intensities that caused complete spike suppression. The third feature is that the magnitudes of the EPSPs evoked by the binaural tones declined in concert with the increasing magnitudes of the IPSPs evoked when tones were presented only to the ipsilateral ear. These features are consistent with the circuitry shown in Figure $1 B$, and thus with the proposition that the EI property in these cells was formed de novo in the IC by the ipsilaterally evoked inhibition that suppressed the contralaterally evoked discharges.

The third type of EI cell was the most common type (20/28 EI cells) and displayed the most surprising feature. The surprising feature is that ipsilateral stimulations evoked intensity-dependent EPSPs. Evidence of ipsilaterally evoked EPSPs was never detected in extracellular studies and thus was not previously proposed as a projection in EI cells.

These EI cells were not homogeneous, but rather displayed one of two intensity-dependent EPSP patterns. In 13/20 EI cells, ipsilateral tones only evoked EPSPs with amplitudes that increased with intensity (Fig. 5). As explained below, the circuit that best accounts for their features is the circuit in Figure $1 A$, but with the addition of an ipsilateral excitatory projection (Fig. $5 C$ ). The addition of the ipsilateral excitatory projection generated a paradoxical feature. The paradox is that the amplitudes of the ipsilaterally evoked EPSPs increased with intensity in each of the 13 cells (Figs. 5F, 6), even though binaural signals with the same ipsilateral intensities generated progressively greater suppressions of contralaterally evoked discharges. When presented binaurally, the highest ipsilateral intensities produced a complete spike suppression, as shown in Figure $5 A$ when ipsilateral intensities were $40-50 \mathrm{~dB}$ SPL.

Importantly, the binaural signal with the highest ipsilateral intensity, e.g., contralateral intensity $(C)=10 \mathrm{~dB}$, ipsilateral intensity $(I)=50 \mathrm{~dB}$ for the cell in Figure 5 , evoked a subthreshold EPSP with a waveform virtually identical in latency, amplitude, and shape to the EPSP evoked by a $50 \mathrm{~dB}$ ipsilateral signal presented alone (Fig. $5 E$ ). What these features suggest is that the spike suppression due to binaural stimulation occurred in a lower nucleus, e.g., the LSO, and that ipsilateral stimulation activated two different projections; one projection inhibited the LSO and another projection provided subthreshold excitation to the IC (Fig. 5C). Thus, with binaural stimulation, increasing ipsilateral

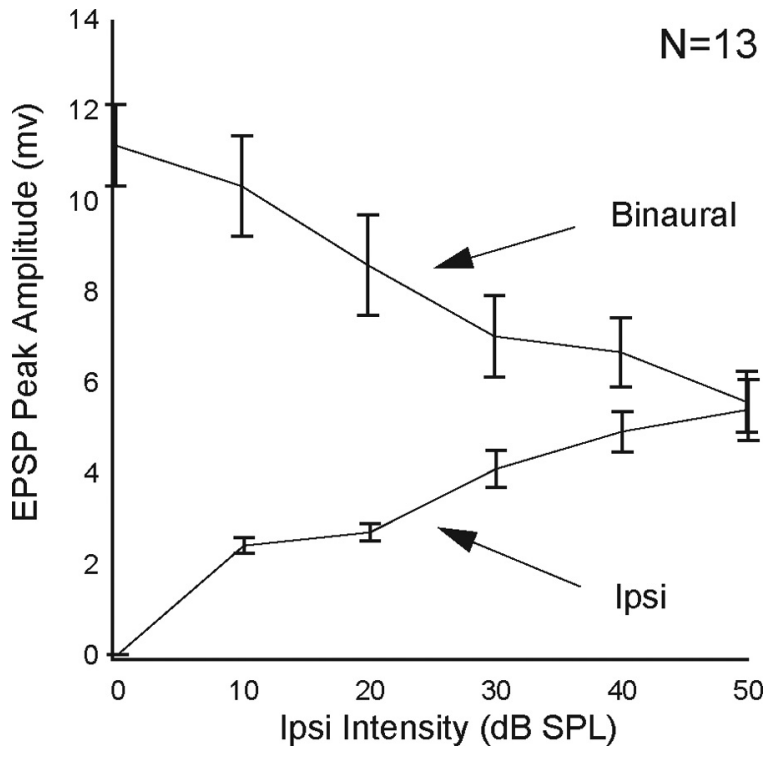

Figure 6. Paradoxical effects of presenting ipsilateral signals monaurally compared to the effects of presenting the same ipsilateral signals binaurally. Increases in amplitudes of the ipsilaterally evoked EPSPs with intensity were in the exact opposite direction to the reduced EPSP amplitudes evoked by the same ipsilateral intensities presented binaurally. Lines connect mean EPSP amplitudes of 13 El cells. The EPSPs of binaural signals that evoked spikes were measured after spikes were filtered from recordings. Error bars show standard error of the mean.

intensities progressively inhibited the excitatory drive from the LSO while simultaneously increasing the subthreshold excitation from the monaural excitatory projection. With IIDs of 30 and 40 $\mathrm{dB}$, ipsilateral ear more intense, the LSO was completely inhibited, leaving only the ipsilaterally evoked excitation. Hence, the PSP evoked by both the monaural ipsilateral signal at $50 \mathrm{~dB}$ and the PSP evoked by the binaural signal that had the same ipsilateral intensity $(C=10, I=50 \mathrm{~dB})$ were virtually the same because they were both evoked only by the ipsilateral excitatory projection.

The paradox of EPSPs evoked by both the contralateral and ipsilateral signals presented alone coupled with a complete spike suppression when the same signals were presented binaurally was also seen in seven other cells. In those cells, however, low ipsilateral intensities evoked IPSPs that then changed into EPSPs, followed by IPSPs at higher ipsilateral intensities (Fig. 7A). The circuit that can account for the monaural and binaural properties of these cells is similar to the circuit proposed for the EI cells with only ipsilaterally evoked EPSPs, but with the further addition of an ipsilaterally evoked inhibitory projection that probably originated in the opposite DNLL (Fig. 7C). The amplitudes of the EPSPs in these cells also increased with ipsilateral intensity, and binaural signals with the same ipsilateral intensities that evoked the largest EPSPs when presented monaurally produced a complete discharge suppression. Moreover, the PSP evoked by the binaural signal with the highest ipsilateral intensity, i.e., $C=30$ $\mathrm{dB}$ SPL, $I=40 \mathrm{~dB}$ SPL in Figure 7E, was similar in latency, shape and magnitude to the PSP evoked by a $40 \mathrm{~dB}$ ipsilateral signal presented alone, as also occurred for the neuron in Figure 5. As we show next, the ipsilaterally evoked EPSPs that we observed in EI cells were also seen in the EI/f cells.

\section{Postsynaptic potentials evoked in EI/f cells}

The main difference between EI and EI/f cells is that facilitated spike counts were evoked over a small range of IIDs at which the ipsilateral signals were either equal to or less intense than the 
A contra
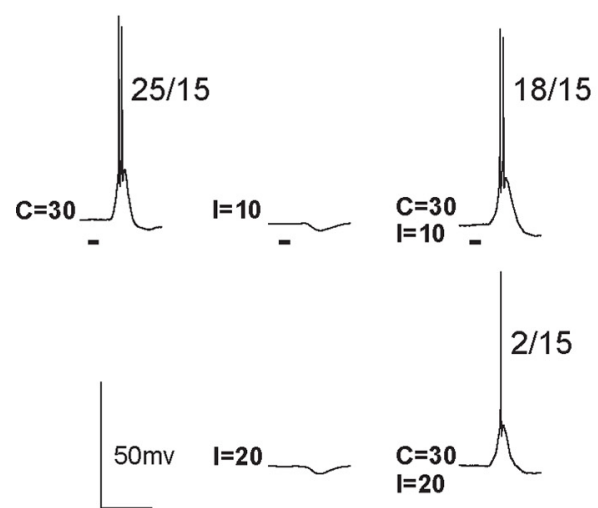

$40 \mathrm{~ms}$

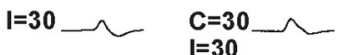

$\mathbf{I = 3 0}$

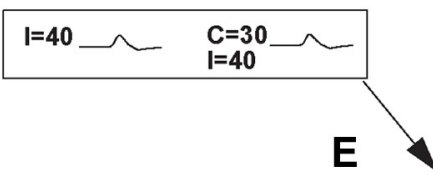

B
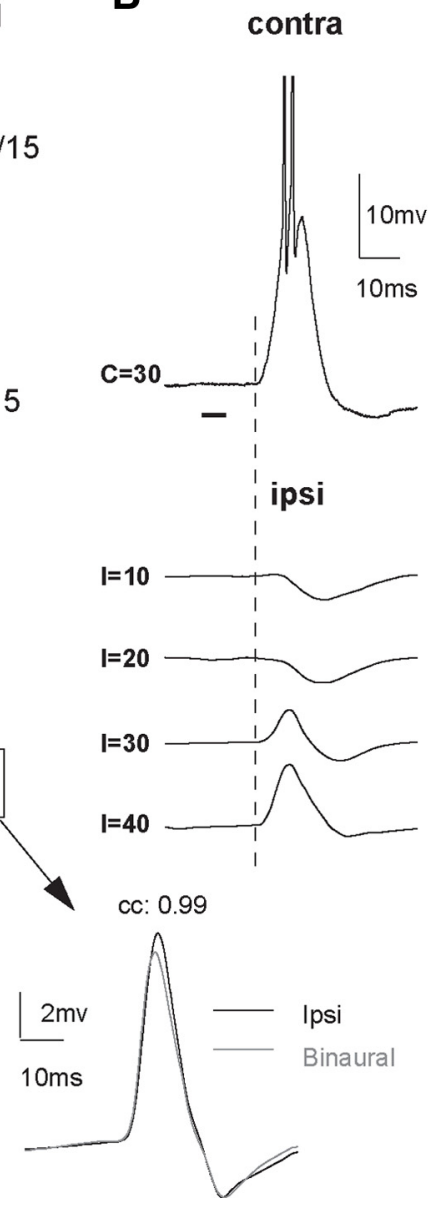

C

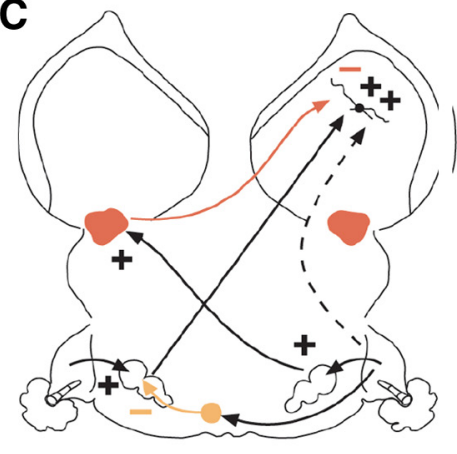

D

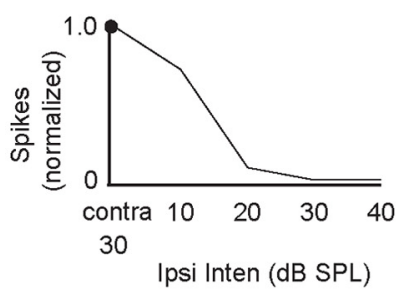

Figure 7. An El cell in which increasing intensity of the ipsilateral tone first evoked IPSPs that changed into prominent EPSPs followed by a shallow IPSP at higher intensities. $\boldsymbol{A}-\boldsymbol{E}$ are the same as in Figure 5. Tone duration, $5.0 \mathrm{~ms}$.

contralateral signals. Since spike counts with binaural tones were enhanced by at least $20 \%$ above the counts evoked by the contralateral tones alone, it would be reasonable to expect that the ipsilateral intensity that evoked facilitation should evoke an EPSP when presented alone. As expected, in most EI/F cells (7/11), ipsilateral tones evoked EPSPs when presented monaurally at the same intensity that evoked facilitation when presented binaurally (Figs. 8A, 9). The EPSP amplitudes ranged from $\sim 2-5 \mathrm{mV}$ and apparently were sufficiently large that the boosts they gave to the contralaterally evoked excitations generated the facilitations. Thus the mechanism that produced the facilitation in these cells apparently was a summation of ipsilaterally and contralaterally evoked EPSPs.

In 4 of the $11 \mathrm{EI} / \mathrm{F}$ cells, however, low-intensity ipsilateral tones presented monaurally evoked virtually no subthreshold response, even though the same ipsilateral signal generated a facilitated response when presented binaurally (Fig. $8 \mathrm{~B}$ ). To confirm that no inputs were evoked by low-intensity ipsilateral signals, we evaluated responses in two cells before and when their membrane potentials were hyperpolarized, and in both cases, low-intensity ipsilateral signals evoked no responses. This is illustrated by the monaural and binaural responses of the cell in Figure $8 B$ when it was hyperpolarized from its normal resting potential of $-57 \mathrm{mV}$ to $-70 \mathrm{mV}$. Ipsilateral tones at the intensity that evoked discharge facilitation (at $0 \mathrm{~dB}$ SPL) did not evoke a PSP under hyperpolarization, although binaural signals evoked a larger EPSP than was evoked by the contralateral tone alone (Fig. $8 C$ ). It would appear that in these cells, the summation of ipsilaterally and contralaterally evoked responses could not account for the facilitation evoked by binaural stimulation. The mechanism of facilitation in these cells is unclear, but the facilitation presumably was initially generated in a lower nucleus.

Binaural signals with ipsilateral intensities higher than those that produced discharge facilitation progressively suppressed spikes in all EI/f cells in a way identical to that described above for conventional EI cells (Fig. 9), and thus the EI property, as opposed to the facilitation, is most likely generated by the same circuit proposed for conventional EI cells with ipsilaterally evoked EPSPs, i.e., Figure $1 A$. As with the majority of the conventional EI cells described previously, EPSPs were evoked by ipsilateral stimulation, and in 10 of $11 \mathrm{EI} / \mathrm{f}$ cells the amplitudes of the ipsilaterally evoked EPSPs increased with intensity. Moreover, with binaural signals the same paradox was observed in these EI/f cells as in the EI cells; the increases in amplitudes of the ipsilaterally evoked EPSPs with intensity were in the exact opposite direction to the reduced spike counts evoked by the same ipsilateral intensities when presented binaurally (Fig. 9A). Finally, the subthreshold EPSPs evoked by binaural signals at high ipsilateral intensities, i.e., 40 and $50 \mathrm{~dB}$ SPL in Figure 9, had the same waveforms and amplitudes as those evoked by ipsilateral signals presented monaurally at 40 and $50 \mathrm{~dB}$ SPL. These results support the proposition presented earlier, that the inputs normally activated by the contralateral ear may have been inhibited at those IIDs in a lower binaural nucleus, and that the EPSPs 


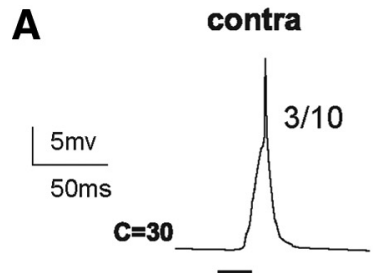

B

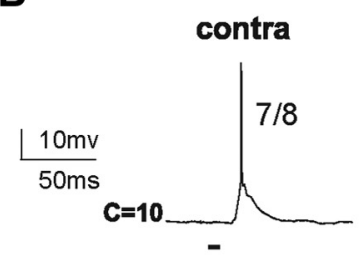

ipsi

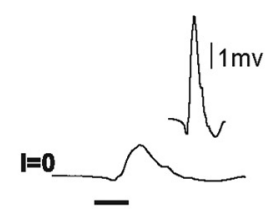

Rest (-57mv) ipsi

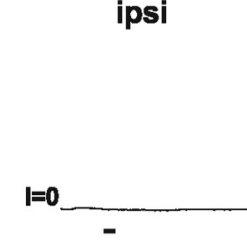

Hyperpolarized (-70mv)
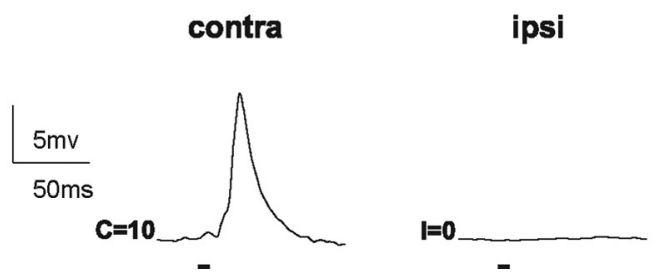
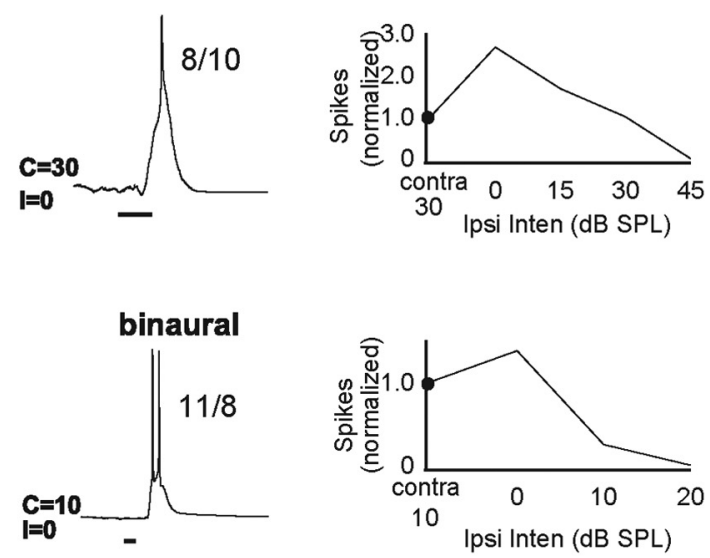

C

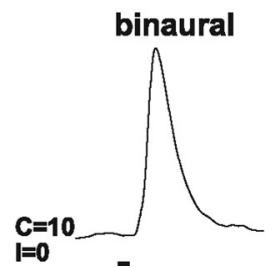

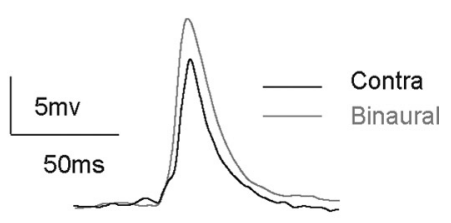

Figure 8. Two El/fcells in which ipsilateral tones evoked different responses when presented monaurally. A, Low ipsilateral intensity ( $0 \mathrm{~dB}$ SPL) evoked an EPSP and spike counts were facilitated with binaural signals that had the same low ( $0 \mathrm{dBSPL}$ ) ipsilateral intensity. Insert shows EPSP in higher magnification. IID function based on normalized spike counts is shown on right. Tone duration, $20.0 \mathrm{~ms}$. B. Another El/f cell in which low ipsilateral intensities (0 dB SPL) did not evoke any response but spike counts were facilitated with binaural signals that had the same ipsilateral intensity $(0 \mathrm{~dB}$ SPL). Top panel shows responses to a contralateral tone at $10 \mathrm{~dB}$ SPL and an ipsilateral tone at $0 \mathrm{~dB}$ SPL, and the facilitated response to tones with the same intensities presented binaurally. Lower panel shows responses to the same stimuli while the cell was hyperpolarized. The EPSP evoked by the binaural signal is slightly larger than EPSP evoked by the contralateral signal alone, even though the ipsilateral tone presented alone evoked no response. C, EPSPs evoked by the contralateral tone and the binaural tone are superimposed. Tone duration, $5.0 \mathrm{~ms}$.

evoked at those IIDs were generated only by the excitatory inputs activated by the ipsilateral ear, as in the circuit shown in Figure 5C.

\section{Binaural response properties at higher contralateral intensities}

The binaural features shown in the previous sections were derived with low-intensity contralateral tones that ranged from 10 to $30 \mathrm{~dB}$ SPL. Ten cells, $7 \mathrm{EI}$ and $3 \mathrm{EI} / \mathrm{f}$ cells, were also evaluated with a second contralateral intensity that was $20-40 \mathrm{~dB}$ more intense than the lower intensity. In each of the 10 cells, the same binaural property evoked with the lower contralateral intensity was also evoked at the higher intensity, which showed that the binaural features were independent of intensity. We illustrate the similar binaural properties at two intensities with the EI cell in Figure 10.

The EI cell in Figure 10 is the same cell shown in Figure 5, but the contralateral intensity in Figure 5 was $10 \mathrm{~dB}$ SPL, whereas the contralateral intensity in Figure 10 was $50 \mathrm{~dB}$ SPL. The circuit that may have generated the responses at $50 \mathrm{~dB}$ is shown in Figure $10 \mathrm{~B}$. The spike count evoked by the $50 \mathrm{~dB}$ SPL contralateral tone was lower than the spike count evoked by the $10 \mathrm{~dB}$ SPL contralateral tone because the cell's rate-intensity function was nonmonotonic (not shown). Thus, the $50 \mathrm{~dB}$ SPL contralateral signal apparently evoked both an excitation and inhibition for reasons given below. In addition, the IID at which spikes were completely suppressed was slightly different with the $50 \mathrm{~dB}$ SPL contralateral tone $(C=50, I=30 \mathrm{~dB})$ than it was for the $10 \mathrm{~dB}$ contralateral tone $(C=10, I=40 \mathrm{~dB})$, presumably due to the smaller spike count evoked by the $50 \mathrm{~dB}$ contralateral signal. In other respects, the binaural properties were similar. For example, whether the contralateral tone was 10 or $50 \mathrm{~dB}$ SPL, the PSPs evoked by binaural stimuli with ipsilateral tones at $50 \mathrm{~dB}$ SPL were almost identical (Fig. 10D). Additionally, those binaurally evoked PSPs were virtually the same as the PSPs evoked by $50 \mathrm{~dB}$ SPL ipsilateral signals presented alone.

The circuit that could explain the cell's response properties incorporates an excitatory projection from the opposite LSO, an ipsilaterally evoked excitatory projection, and an additional inhibitory input driven by high but not low contralateral intensities. Since LSO neurons have monotonic rate-intensity functions (Tsuchitani and Boudreau, 1967; Tsuchitani and Johnson, 1985; Park et al., 1997), the additional inhibitory input would account for the nonmonotonic rate-intensity function of the IC cell. The nucleus that provided that inhibition was almost certainly binaural because there was no evidence of contralateral inhibition with the binaural tones at $C=50, I=50$ (Fig. 10A). The contralateral inhibition may have come from the DNLL on the same side as the IC, since the DNLL is a binaural nucleus with EI properties (Brugge et al., 1970; Yang and Pollak, 1994; Kelly et al., 1998) that provides inhibitory projections bilaterally to EI cells in the IC (Adams and Mugnaini, 1984; Shneiderman et al., 1988; Ross and Pollak, 1989; Shneiderman and Oliver, 1989; Winer et al., 1995). We propose that the $50 \mathrm{~dB}$ contralateral signal drove two lower binaural inputs, excitation from the LSO and inhibition from the DNLL on the same side as the IC (Fig. $10 \mathrm{~B}$ ). The ipsilateral signal drove three inputs: one that inhibited the LSO, one that inhibited the DNLL, and a third that evoked a subthreshold excitation. As the ipsilateral intensity was increased in the binaural signals, the inputs from the ipsilateral ear progressively inhibited both the 

A contra<smiles>C=CC(C)C(C)O</smiles><smiles>[Te]=C[Fe]=[Te]</smiles>

I=10

$1=20$

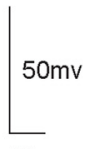

$30 \mathrm{~ms}$

ipsi

$\mid=3$ binaural
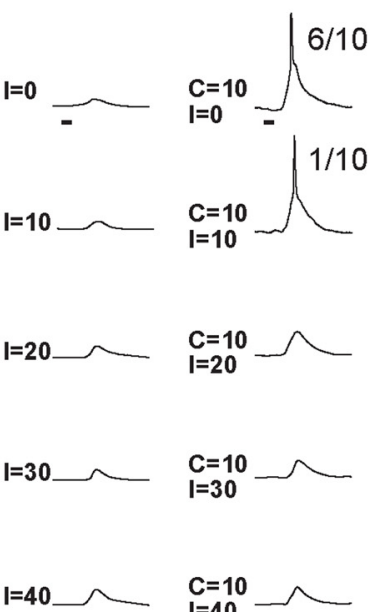

$\mathrm{C}=10$
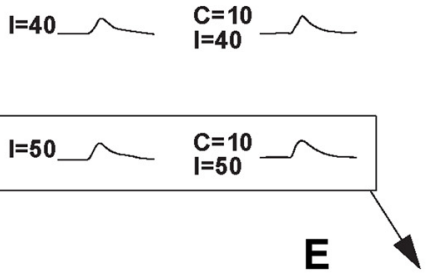

E

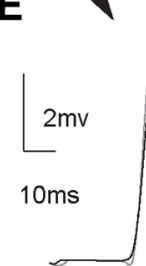

B

B contra
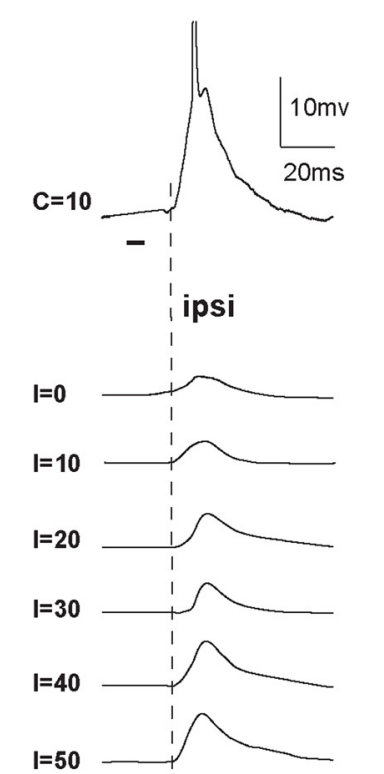

$\mathbf{I}=\mathbf{5 0}$ cc: 0.98
C

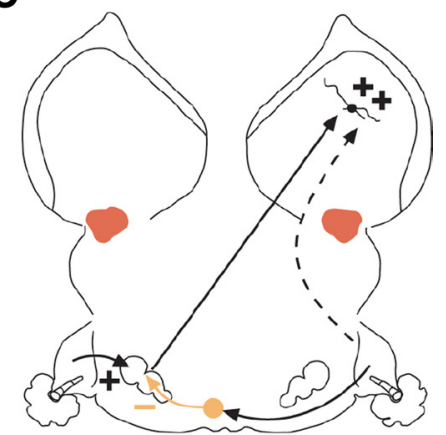

D

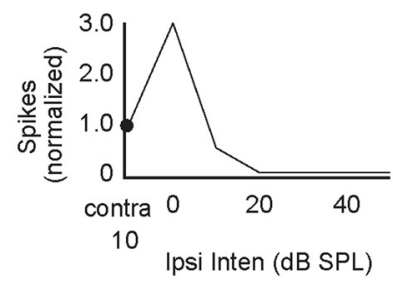

Figure 9. El/f cell in which ipsilateral tones evoked only EPSPs and facilitation was apparently produced by a summation of excitations evoked by ipsilateral and contralateral tones. Higher ipsilateral intensities evoked progressively larger EPSPs but suppressed discharges when presented binaurally. $\boldsymbol{A}-\boldsymbol{E}$ are the same as in Figure 5 . The amplitude of the ipsilateral EPSP in $\boldsymbol{E}$ is $\sim 8.0 \mathrm{mV}$.

excitation from the LSO and the inhibition from the DNLL, while increasing the excitation to the IC. When the ipsilateral intensity was 40 or $50 \mathrm{~dB}$ SPL, both the excitation from the LSO and the inhibition from the DNLL were completely suppressed, leaving only the ipsilaterally evoked excitation. Such a circuit would account for the identity of the PSPs evoked by binaural signals with $50 \mathrm{~dB}$ SPL ipsilateral intensities with contralateral signals of 10 and $50 \mathrm{~dB}$ SPL, even though a higher-intensity contralateral signal presented alone evoked both an excitation and inhibition.

\section{Discussion}

This study showed five major features of EI and EI/f cells in the IC. The first is that a minority of EI cells inherited their response properties from a lower binaural nucleus. Those cells were in essence "monaural" in that they received excitatory inputs only from the contralateral ear and received no innervation from the ipsilateral ear. The second feature is that the EI property in a few cells was formed de novo in the IC via excitatory projections from the contralateral ear that were suppressed in the IC by inhibitory projections from the ipsilateral ear. The third, and most surprising feature, was that the majority of EI cells received excitatory inputs not only from the contralateral ear, but also from the ipsilateral ear, and in many of those cells, ipsilateral stimulation evoked only EPSPs. The fourth feature concerns EI/f cells, and is that EPSPs were evoked by ipsilateral stimulation at IIDs that evoked facilitation. Finally, the fifth feature is that in almost all EI/f cells, EPSPs were evoked by ipsilateral stimulation at IIDs that suppressed contralaterally evoked spikes, in ways identical to conventional EI cells. Below we discuss how these results compare to previous studies and then propose some functional consequences for the ipsilaterally evoked EPSPs that were so commonly observed in both EI and EI/f cells.

\section{Comparisons with previous studies}

Previous studies showed that EI and EI/f cells comprise a diverse subpopulation of the IC, since each type is formed by different circuitry (Faingold et al., 1989, 1993; Li and Kelly, 1992; Park and Pollak, 1993, 1994). The circuits proposed in previous studies are shown in Figure $1 A-C$ and invoked various combinations of three projections: (1) the projection of the LSO to the contralateral IC, (2) the projections of the DNLL to the contralateral IC, and (3) an excitatory projection of unknown source from a lower monaural nucleus that was activated by stimulation of the ear contralateral to the IC. Our results can, with the addition of a circuit for ipsilateral evoked EPSPs, be explained by the three projections and are largely in agreement with previous studies. Thus, previous extracellular studies reported that the EI properties of some cells were unchanged when inhibition was blocked or when the contralateral DNLL was reversibly inactivated (Fig. $1 A)$. Those cells are directly comparable to the EI cells we recorded in which ipsilateral stimulation evoked no subthreshold response at any intensity, and must have inherited their EI properties from the LSO. Previous studies also showed that the spike suppression in other EI cells was due to inhibitory projections from the opposite DNLL (Fig. $1 B$ ). In those studies, spike sup- 
pression with binaural stimuli was abolished when the DNLL on the side opposite to the IC was inactivated, and the spike suppression then returned following inactivation (Li and Kelly, 1992; Faingold et al., 1993; Burger and Pollak, 2001). The changes in EI properties of the cells due to DNLL inactivation are strikingly similar to the EI cells in which contralateral stimulation evoked excitation and ipsilateral stimulation evoked IPSPs, where the amplitudes of the IPSPs increased with ipsilateral sound intensity (e.g., the cell in Fig. 4).

The projection that was not proposed in previous studies is a subthreshold EPSP evoked by ipsilateral stimulation, since that response was undetectable with extracellular recordings even when inhibition was blocked. Indeed, it seems likely that some of the EI cells in previous extracellular studies that were unaffected when inhibition was blocked were cells that inherited their EI property from LSO projections but also had ipsilaterally evoked, subthreshold EPSPs. The EI properties would not change when inhibition was blocked because the EI property itself is first generated in the LSO, in the same way described above for cells that inherit their EI property but have no ipsilaterally evoked responses. The scenario for EI cells with EPSPs is that low intensities at the ipsilateral ear evoke no subthreshold responses, but with increasing ipsilateral intensities the LSO is progressively inhibited, while the amplitude of the ipsilateral EPSP progressively grows. The ipsilaterally evoked EPSPs presumably add to the decreasing EPSPs from the LSO, which would adjust the IID at which the cell is completely inhibited so that higher intensities at the ipsilateral ear would be required to completely inhibit the cell than if the cell only received projections from the LSO. At IIDs with high ipsilateral intensities, the LSO is completely inhibited, leaving only a subthreshold EPSP evoked by the ipsilateral ear, which would not be detected when inhibition was blocked because it was subthreshold. This interpretation is supported by the EPSPs in both EI and EI/f cells evoked by binaural stimulation at IIDs with ipsilateral intensities $10-40 \mathrm{~dB}$ higher than the contralateral intensity. In all of these cells, the binaurally evoked EPSPs were virtually identical to the EPSPs evoked only by ipsilateral stimulation at the same intensity as in the binaural signals.

Other EI cells had ipsilaterally evoked inhibition and an ipsilaterally evoked subthreshold excitation that was activated at intensities higher than those that activated the inhibition (Fig. 7). Their EI property is probably inherited from the LSO and is further shaped by an ipsilaterally evoked inhibition at low IIDs that may have originated from the opposite DNLL. These features are consistent with some cells in previous extracellular studies in which blocking GABAergic inhibition did not eliminate their EI property but rather changed the IID that caused a complete or nearly complete inhibition (Faingold et al., 1989; Li and Kelly, 1992; Park and Pollak, 1993).

The same circuitry that we proposed for the EI cells with ipsilateral EPSPs could also account for the EI/f cells that expressed ipsilateral EPSPs at the IIDs that evoked facilitation. The only difference in the EI/f cells is that the circuit that generates the ipsilateral EPSPs has lower thresholds than the ipsilateral circuits in the conventional EI cells. In this scenario, binaural signals with low ipsilateral intensities would evoke both the excitation from the LSO and a small ipsilaterally evoked EPSP whose summation would generate a spike count greater than that evoked only by the LSO excitation, and thereby evoke the facilitation.

\section{Potential functional consequences of the ipsilaterally evoked EPSPs}

What functional impact could the ipsilaterally evoked EPSPs have on binaural processing of sound for localization? One possibility is that their influence would be apparent only in more 
complex acoustic environments with moving sounds or when several sounds are received in succession. Consider, for example, a sound that moves around the head from the ipsilateral to the contralateral sound field. The initial EPSP could summate with the stronger excitation evoked as the sound moves into the contralateral field and thereby evoke a stronger discharge than would a stationary sound in the contralateral sound field. Another possibility applies to two or more sounds that followed each other within a short interval and that emanate from the same location in space, a location that generates an IID more intense at the ipsilateral ear. The first sound would evoke only a subthreshold EPSP, while the EPSP evoked by the following sound(s) would summate with the first EPSP. Assuming the summated response is suprathreshold, there would be a change in the responsiveness of the IC cell for the trailing sound(s) produced by the reception of an earlier sound whose IID only generates a subthreshold EPSP.

It is noteworthy that such a change in responsiveness to a trailing signal occurs in neurons whose EI properties are formed de novo in the IC through GABAergic projections from the opposite DNLL (Burger and Pollak, 2001; Pollak et al., 2003; Pecka et al., 2007). In those cells, initial signals with IIDs that are stronger in the contralateral ear allow the cell to discharge to trailing signals with IIDs that, when presented alone, completely suppress discharges. Such changes in the binaural sensitivities of EI cells have been shown to contribute to the precedence effect, a percept common to all animals (Wyttenbach and Hoy, 1993; Keller and Takahashi, 1996, 2005; Burger and Pollak, 2001; Pecka et al., 2007). The precedence effect is caused by a mechanism that suppresses the directional information carried by echoes (Wallach et al., 1949; Zurek, 1987; Litovsky et al., 1999; Pecka et al., 2007). When initial and trailing sounds are presented, listeners hear a single composite sound and perceive the composite sound as originating from the leading speaker.

The difference between cells that express ipsilateral EPSPs and those that express inhibition to ipsilateral signals is that the EPSPs could change the responsiveness to signals that emanate from the same locations in space, whereas cells that express ipsilateral inhibition only change the responsiveness to signals that emanate from different regions of space. Together, the two types of cells could respond to trailing signals from any region of space while degrading the code for the location of the trailing sound. Previous studies suggested that dynamic IIDs generate different responses in IC cells than do static IIDs (Sanes et al., 1998; Burger and Pollak, 2001). Given the prevalence of ipsilaterally evoked EPSPs among EI cells, features that change binaural processing in dynamic acoustic environments may be more prevalent than previously suspected.

\section{References}

Adams JC, Mugnaini E (1984) Dorsal nucleus of the lateral lemniscus: a nucleus of GABAergic projection neurons. Brain Res Bull 13:585-590.

Brugge JF, Anderson DJ, Aitkin LM (1970) Responses of neurons in the dorsal nucleus of the lateral lemniscus of cat to binaural tonal stimulation. J Neurophysiol 33:441-458.

Burger RM, Pollak GD (2001) Reversible inactivation of the dorsal nucleus of the lateral lemniscus reveals its role in the processing of multiple sound sources in the inferior colliculus of bats. J Neurosci 21:4830-4843.

Caird D, Klinke R (1983) Processing of binaural stimuli by cat superior olivary S-segment. Exp Brain Res 52:385-399.

Casseday JH, Fremouw T, Covey E (2002) The inferior colliculus: a hub for the central auditory system. In: Integrative functions in the mammalian auditory pathway, Vol 15 (Oertel D, Popper AN, Fay RR, eds), pp 238 318. New York: Springer.
Erulkar SD (1972) Comparative aspects of spatial localization of sounds. Physiol Rev 52:237-360.

Faingold CL, Gehlbach G, Caspary DM (1989) On the role of GABA as an inhibitory neurotransmitter in inferior colliculus neurons: iontophoretic studies. Brain Res 500:302-312.

Faingold CL, Anderson CA, Randall ME (1993) Stimulation or blockade of the dorsal nucleus of the lateral lemniscus alters binaural and tonic inhibition in contralateral inferior colliculus neurons. Hear Res 69:98-106.

Fuzessery ZM, Wenstrup JJ, Pollak GD (1985) A representation of horizontal sound location in the inferior colliculus of the mustache bat (Pteronotus p. parnellii). Hear Res 20:85-89.

Gittelman JX, Li N, Pollak GD (2009) Mechanisms underlying directional selectivity for frequency modulated sweeps in the inferior colliculus revealed by in vivo whole-cell recordings. J Neurosci 29:13030-13041.

Irvine DR, Gago G (1990) Binaural interaction in high frequency neurons in the inferior colliculus of he cat: effects of variation in sound pressure level on sensitivity to interaural intensity disparities. J Neurophysiol 63:570-591.

Joris PX, Yin TC (1995) Envelope coding in the lateral superior olive. I. Sensitivity to interaural time differences. J Neurophysiol 73:1043-1062.

Keller CH, Takahashi TT (1996) Responses to simulated echoes by neurons in the barn owl's auditory space map. J Comp Physiol A 178:499-512.

Keller CH, Takahashi TT (2005) Localization and identification of concurrent sounds in the owl's auditory space map. J Neurosci 25:10446-10461.

Kelly JB, Glenn SL, Beaver CJ (1991) Sound frequency and binaural response properties of single neurons in rat inferior colliculus. Hear Res 56:273-280.

Kelly JB, Buckthought AD, Kidd SA (1998) Monaural and binaural response properties of single neurons in the rat's dorsal nucleus of the lateral lemniscus. Hear Res 122:25-40.

Li L, Kelly JB (1992) Inhibitory influence of the dorsal nucleus of the lateral lemniscus on binaural responses in the rat's inferior colliculus. J Neurosci 12:4530-4539.

Litovsky RY, Colburn HS, Yost WA, Guzman SJ (1999) The precedence effect. J Acoust Soc Am 106:1633-1654.

Mills AW (1972) Auditory localization. In: Foundations of modern auditory theory, Vol II (Tobias JV, ed), pp 303-348. New York: Academic.

Moore MJ, Caspary DM (1983) Strychnine blocks binaural inhibition in lateral superior olivary neurons. J Neurosci 3:237-242.

Oliver DL, Huerta MF (1992) Inferior and superior colliculi. In: The mammalian auditory system: neuroanatomy (Webster DB, Popper AN, Fay RR, eds), pp 168-221. New York: Springer.

Park TJ, Pollak GD (1993) GABA shapes sensitivity to interaural intensity disparities in the mustache bat's inferior colliculus: implications for encoding sound location. J Neurosci 13:2050-2067.

Park TJ, Pollak GD (1994) Azimuthal receptive fields are shaped by GABAergic inhibition in the inferior colliculus of the mustache bat. J Neurophysiol 72:1080-1102.

Park TJ, Grothe B, Pollak GD, Schuller G, Koch U (1996) Neural delays shape selectivity to interaural intensity differences in the lateral superior olive. J Neurosci 16:6554-6566.

Park TJ, Monsivais P, Pollak GD (1997) Processing of interaural intensity differences in the LSO: role of interaural threshold differences. J Neurophysiol 77:2863-2878.

Pecka M, Zahn TP, Saunier-Rebori B, Siveke I, Felmy F, Wiegrebe L, Klug A, Pollak GD, Grothe B (2007) Inhibiting the inhibition: a neuronal network for sound localization in reverberant environments. J Neurosci 27:1782-1790.

Pollak GD, Burger RM, Klug A (2003) Dissecting the circuitry of the auditory system. Trends Neurosci 26:33-39.

Ross LS, Pollak GD (1989) Differential ascending projections to aural regions in the $60 \mathrm{kHz}$ contour of the mustache bat's inferior colliculus. J Neurosci 9:2819-2834.

Roth GL, Aitkin LM, Andersen RA, Merzenich MM (1978) Some features of the spatial organization of the central nucleus of the inferior colliculus of the cat. J Comp Neurol 182:661-680.

Sanes DH, Malone BJ, Semple MN (1998) Role of synaptic inhibition in processing of dynamic binaural level stimuli. J Neurosci 18:794-803.

Semple MN, Kitzes LM (1987) Binaural processing of sound pressure level in the inferior colliculus. J Neurophysiol 57:1130-1147. 
Shneiderman A, Oliver DL (1989) EM autoradiographic study of the projections from the dorsal nucleus of the lateral lemniscus: a possible source of inhibitory inputs to the inferior colliculus. J Comp Neurol 286:28-47.

Shneiderman A, Oliver DL, Henkel CK (1988) Connections of the dorsal nucleus of the lateral lemniscus: an inhibitory parallel pathway in the ascending auditory system? J Comp Neurol 276:188-208.

Tsuchitani C, Boudreau JC (1967) Encoding of stimulus frequency and intensity by cat superior olive S-segment cells. J Acoust Soc Am 42:794-805.

Tsuchitani C, Johnson DH (1985) The effects of ipsilateral tone burst stimulus level on the discharge patterns of cat lateral superior olivary units. J Acoust Soc Am 77:1484-1496.

Wallach H, Newman EB, Rosenzweig MR (1949) The precedence effect in sound localization. Am J Psychol 62:315-336.

Wenstrup JJ, Ross LS, Pollak GD (1986) Binaural response organization within a frequency-band representation of the inferior colliculus: implications for sound localization. J Neurosci 6:962-973.

Winer JA, Larue DT, Pollak GD (1995) GABA and glycine in the central auditory system of the mustache bat: structural substrates for inhibitory neuronal organization. J Comp Neurol 355:317-353.

Wyttenbach RA, Hoy RR (1993) Demonstration of the precedence effect in an insect. J Acoust Soc Am 94:777-784.

Xie R, Gittelman JX, Li N, Pollak GD (2008) Whole cell recordings of intrinsic properties and sound-evoked responses from the inferior colliculus. Neuroscience 154:245-256.

Yang L, Pollak GD (1994) The roles of GABAergic and glycinergic inhibition on binaural processing in the dorsal nucleus of the lateral lemniscus of the mustache bat. J Neurophysiol 71:1999-2013.

Zurek PM (1987) The precedence effect. In: Directional hearing (Yost WA, Gourevitch G, eds), pp 85-105. New York: Springer. 